\title{
Intrahepatic Xenograft of Cutaneous T-Cell Lymphoma Cell Lines
}

\section{A Useful Model for Rapid Biological and Therapeutic Evaluation}

Laetitia Andrique, ${ }^{*}$ Sandrine Poglio, ${ }^{\star}$ Martina Prochazkova-Carlotti, ${ }^{*}$ Marshall Edward Kadin, ${ }^{\dagger}$ Alban Giese, ${ }^{\ddagger}$ Yamina Idrissi, ${ }^{*}$ Marie Beylot-Barry, ${ }^{\circledR}$ Jean-Philippe Merlio, ${ }^{* \mathbb{T}}$ and Edith Chevret*

From the Cutaneous Lymphoma Oncogenesis Team, ${ }^{*}$ INSERM U1053 BordeAux Research in Translational Oncology, and the Histology Platform Service Mixed Unit TransBioMed Core, ${ }^{\ddagger}$ Bordeaux University, Bordeaux, France; the Department of Dermatology, ${ }^{\dagger}$ Boston University and Roger Williams Medical Center, Providence, Rhode Island; the Department of Dermatology, ${ }^{\S}$ University Hospital Center Bordeaux, Bordeaux, France; and the Tumor Bank and Tumor Biology Laboratory, "University Hospital Center Bordeaux, Pessac, France

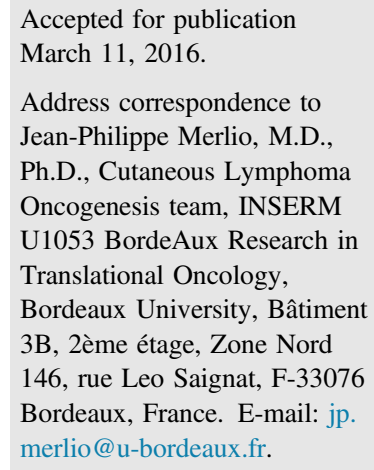

\begin{abstract}
Cutaneous T-cell lymphomas (CTCLs) are a heterogeneous group of diseases primarily involving the skin that could have an aggressive course with circulating blood cells, especially in Sézary syndrome and transformed mycosis fungoides. So far, few CTCL cell lines have been adapted for in vivo experiments and their tumorigenicity has not been adequately assessed, hampering the use of a reproducible model for CTCL biological evaluation. In fact, both patient-derived xenografts and cell line xenografts at subcutaneous sites failed to provide a robust tool, because engraftment was dependent on mice strain and cell line subtype. Herein, we describe an original method of intrahepatic injection into adult NOD.Cg-Prkdc ${ }^{\text {scid }}$ Il2 $\mathrm{rg}^{\text {tm1 Wjl }} / \mathrm{SzJ}$ mice liver of both aggressive (My-La, HUT78, HH, MAC2A, and MAC2B) and indolent (FE-PD and MAC1) CTCL cell lines. Six of the seven CTCL cell lines were grafted with a high rate of success $(80 \%)$. Moreover, this model provided a quick (15 days) and robust assay for in vivo evaluation of CTCL cell lines tumorigenicity and therapeutic response in preclinical studies. Such a reproducible model can be therefore used for further functional studies and in vivo drug testing. (Am J Pathol 2016, 186: 1775-1785; http://dx.doi.org/10.1016/j.ajpath.2016.03.012)
\end{abstract}

Cutaneous T-cell lymphomas (CTCLs) are a heterogeneous group of diseases primarily involving the skin, which presumably derives from skin-homing T-cells exhibiting important differences according to their circulating capacities in the peripheral blood and lymph node involvement. ${ }^{1,2}$ The present research focuses on the three main CTCL subtypes: mycosis fungoides (MF), Sézary syndrome (SS), and primary $\mathrm{CD}^{+} 0^{+}$cutaneous anaplastic large-cell lymphoma. Patients with cutaneous anaplastic large-cell lymphoma present solitary or localized skin nodules or tumors of nonepidermotropic infiltrate of large $\mathrm{CD} 30^{+}$T-cells. ${ }^{3}$ Despite a good prognosis, ${ }^{4}$ cutaneous anaplastic large-cell lymphoma may be harmful in approximately one-third of patients presenting large tumor skin lesions and/or multiple skin relapses. On the other hand, at early or patch/plaque stage, MF is a skin-limited variant of CTCL with fixed lesion(s) containing malignant cells with a skin resident effector memory T-cell phenotype. In contrast, SS is an aggressive leukemic CTCL subtype where malignant cells coexpress both T-central memory markers and skin-homing

Supported by the University Hospital Center Bordeaux PHRC CACLYT, the PHRC REV-LEG (Bordeaux University Hospital Center 2011/28-REVLEG), the French Society of Dermatology, Committee of the Dordogne, The Cancer League grant, and Integrated Sites of Cancer Research - Bordeaux Oncology Integrated Research National Cancer Institute Department of National Health-Inserm 6046 grant (L.A.).

Disclosures: None declared. 
addressing with recirculating capacities between blood and skin. ${ }^{2,5}$ Together with advanced stage MF (tumor and/or large-cell transformed MF), SS represents the most aggressive form of CTCL. In these aggressive forms, malignant T-cells spread to several sites, including skin, blood, and lymph nodes. However, the mechanisms of tumor cell migration out of the skin are so far poorly understood, especially in patients with MF who may have a circulating dominant clone. ${ }^{6}$ To date, there is no model to assess cellular changes associated with migration and spreading into different tissue compartments.

Few CTCL cell lines are available and most of them have been derived from blood samples of patients with CTCL (Table 1). ${ }^{7-13}$ In our hands, compared with other leukemia cell lines, CTCL cell lines present a low mitotic index. This phenomenon could be linked to intrinsic biological or genetic properties, such as the shortening of telomeres in aggressive CTCL cell lines, ${ }^{14}$ and several of them are rather difficult to transduce. These constraints hamper biological investigation. Improvement in development of cell lines together with the generation of robust in vivo mouse xenograft models are needed to test phenotypic or biological changes during tumor formation and migration as well as to evaluate new therapies targeting biological pathways. Some rare patient-derived xenografts or cell line xenografts have been obtained by subcutaneous injection or intravenous tail injection of cells in grafted animals but did not generate a new cell line or a generalized model because their success was found to be mice strain and/or cell line dependent. ${ }^{15-21}$
In 2012, van der Fits et $\mathrm{al}^{22}$ described an original mouse model by xenotransplantation of two SS cell lines (HUT78 and $\mathrm{SeAx}$ ) and fresh patient cells in newborn $R A G 2^{-/-} \mathrm{\gamma c}^{-/-}$ mice liver (2 to 7 days old). This model gave some interesting preliminary results, but the mice number was low and since their report, no further data were claimed using this model for CTCL engraftment.

In the current study, we developed a highly reproducible intrahepatic model of CTCL in a large cohort of adult immunodeficient NSG mice (NOD.Cg-Prkdc scid $I l 2 \mathrm{rg}^{t m l W j l} /$ SzJ). For six of seven CTCL cell lines, mice rapidly developed liver tumors with a high successful rate of engraftment $(80 \%)$ with cell spreading into organs. The present model opens the door to further preclinical models to assess single or multiagent therapies and in vivo evaluation of CTCL proliferation, tumor growth, and migration.

\section{Materials and Methods}

\section{Cell Lines}

Experiments were conducted on five aggressive CTCL cell lines, My-La (kindly gifted by Dr. Kaltof, Aarhus University, Denmark), HUT78 (ATCC, Molesheim, France), HH (DSMZ, Braunschweig, Germany), MAC2A, and MAC2B (DSMZ), and two indolent CTCL cell lines, FE-PD (Prof. Delsol, Inserm U563, Toulouse, France) and MAC1 (DSMZ). Cells were grown at $37^{\circ} \mathrm{C}$ in $5 \% \mathrm{CO}_{2}$ in RPMI 1640 media containing $10 \%$ fetal bovine serum, except

Table 1 In Vitro Clonogenicity and in Vivo Intrahepatic Tumorigenicity of CTCL Cell Lines

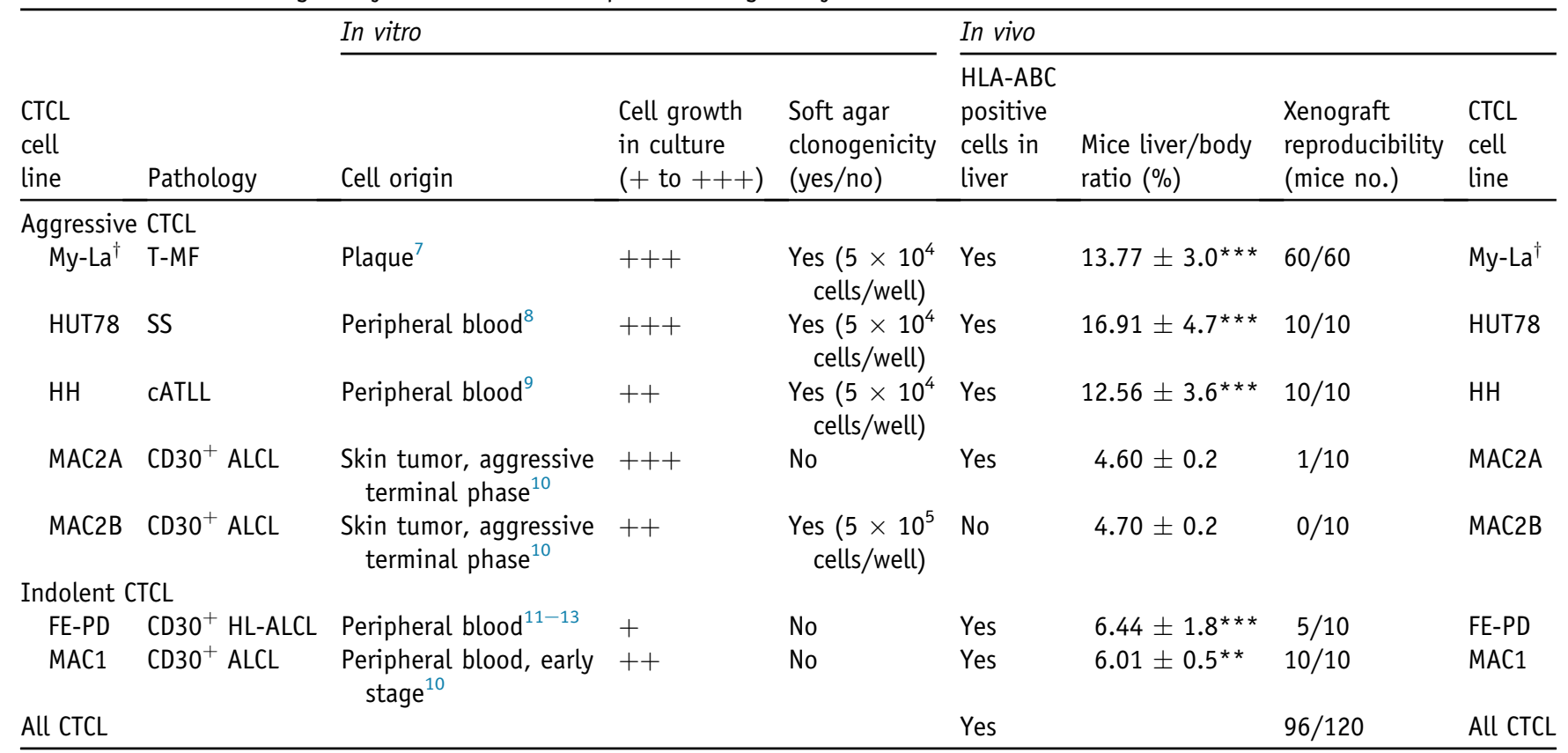

Liver/body weight ratio is expressed as means \pm SD.

${ }^{* *} P<0.01,{ }^{* * *} P<0.001$.

${ }^{\dagger}$ My-La cell line was in our hand the only cell line giving a reproducible engraftment after subcutaneous injection.

CATLL, cutaneous adult T-cell leukemia/lymphoma; CTCL, cutaneous T-cell lymphoma; HL-ALCL, Hodgkin-like anaplastic large-cell lymphoma; SS, Sézary syndrome; T-MF, transformed mycosis fungoides; + , slow; ++ , medium; +++ , fast. 
FE-PD, which required Iscove's modified Dulbecco's medium supplemented with $20 \%$ fetal bovine serum. Cell lines were regularly tested for the absence of mycoplasma contamination.

\section{Soft Agar Assays}

A total of $5 \times 10^{4}, 10 \times 10^{4}$, or $5 \times 10^{5}$ cells per well (6-well plates) were cultured in soft agar to determine CTCL cell line clonogenicity. Soft agar assays were performed as previously described. ${ }^{14}$

\section{Ethics Statement}

Animal experiments were performed in level 2 animal facilities, Bordeaux University, in accordance with national institutional guidelines and with the agreement of the local Ethic Committee on Animal Experiments CEEA50 of Bordeaux (agreement number 50120151-A).

\section{Intrahepatic Mouse Model}

A total of $5 \times 10^{6}$ cells were intrahepatically xenografted in adult (aged 8 to 12 weeks) NSG immunodeficient mice (NOD.Cg-Prkdc ${ }^{\text {scid }} I l 2 \mathrm{rg}^{\mathrm{tml} / \mathrm{Wjl}} / \mathrm{SzJ}$ ) under $2.5 \%$ isoflurane anesthesia (Belamont, Piramal Healthcare, Northumberland, UK). Body weight was daily measured with a global surveillance of animal health. At 4 to 5 weeks after engraftment, mice were sacrificed, body and liver weights were measured, and liver/body ratio was then determined. Liver, spleen, kidneys, heart, and lungs were fixed in $4 \%$ formaldehyde (MERCK Millipore, VWR International S.A.S, Fontenay-sous-Bois, France) for immunohistochemistry (IHC). A total of 60 mice were intrahepatically grafted for My-La cell line. Ten mice were grafted for each other cell line (HUT78, FE-PD, HH, MAC1, MAC2A, and MAC2B).

\section{IHC}

Mayer's hematoxylin labeling and human leukocyte antigen (HLA-ABC) IHC were performed on mice organ sections (3 $\mu \mathrm{m}$ thick) (1:100 of Antibody 70328; Abcam, Paris, France) of formalin-fixed, paraffin-embedded organs. Slides were analyzed using Pannoramic Scan (3DHISTECH, Budapest, Hungary) and Pannoramic Viewer software version 1.15.4 (3DHISTECH) or using microscope LEICA DMR coupled with a camera NIKON DS-FI2 and NIS BR imaging software version 4.0 (Nikon, Champigny sur Marne, France).

\section{MTX in Vitro Treatment}

My-La cells were treated for 72 hours with methotrexate (MTX), 10 and $50 \mu \mathrm{mol} / \mathrm{L}$ (Mylan Laboratory, Saint-Priest, France), or left untreated, as control. Cell number was counted and analyzed at 48 and 72 hours.

\section{MTX in Vivo Mice Treatment}

A total of $2.5 \times 10^{6}$ My-La cells were intrahepatically grafted in 20 NSG mice. Three days after engraftment, 10 mice were treated with $0.5 \mathrm{mg} / \mathrm{kg}$ of MTX, or left untreated as control. Treatment was daily conducted by intraperitoneal injection during 12 days. At sacrifice (day 15), organs were fixed in $4 \%$ formaldehyde for IHC or mechanically dissociated before fluorescence-activated cell sorter (FACS) analysis.

\section{FACS Analysis}

Human Cell Detection

HLA-ABC was detected in single-cell suspensions obtained from mice organs, using a PE-Cy7 antibody (561349; BD Biosciences, Le Pont de Claix, France). Detection was conducted using BD FACS Canto II, and results were analyzed by FlowJo software version 10 (Tree Star Inc., Ashland, OR).

\section{Apoptosis/Necrotic Cell Detection}

Apoptotic/necrotic cell proportion was measured using annexin $\mathrm{V}-\mathrm{PE}$ antibody (BD Biosciences), according to the manufacturer's recommendations, and Hoechst 33342 (H3570; Molecular Probes, Eugene, OR) was added 5 minutes before sample acquisition. Apoptosis/necrosis was analyzed on FACS Canto II cytometer (BD Biosciences) using FlowJo software.

\section{Statistical Analysis}

Statistical analysis was performed with MedCalc software version 12.3 (MedCalc Software, Mariakerke, Belgium). For nonparametric statistical analysis, the Wilcoxon-MannWhitney test was used. $P<0.05$ was considered statistically significant.

\section{Results}

\section{Intrahepatic Xenograft Model for My-La Cells}

To test the feasibility of a new intrahepatic xenograft model of CTCL in adult immunodeficient mice, we used My-La cells previously reported as the most aggressive CTCL cell line for both in vitro and in vivo subcutaneous xenograft models. ${ }^{18}$ Herein, $5 \times 10^{6}$ My-La cells were xenografted intrahepatically in 60 adult mice ( 8 to 12 weeks old). Tumor formation was characterized by rapid macroscopically visible liver tumors (3 weeks) and disseminated intrahepatic nodules in all of the 60 grafted mice (Figure 1A). IHC of formalin-fixed, paraffinembedded mice liver sections (Figure 1B) was used to detect ubiquitous HLA-ABC in all of the 60 mice livers. Liver/body weight ratio significantly increased between My-La xenografted mice and nongrafted control mice $(13.77 \% \pm 3.0 \%$ versus $4.60 \% \pm 0.5 \% ; P<0.001)$ 


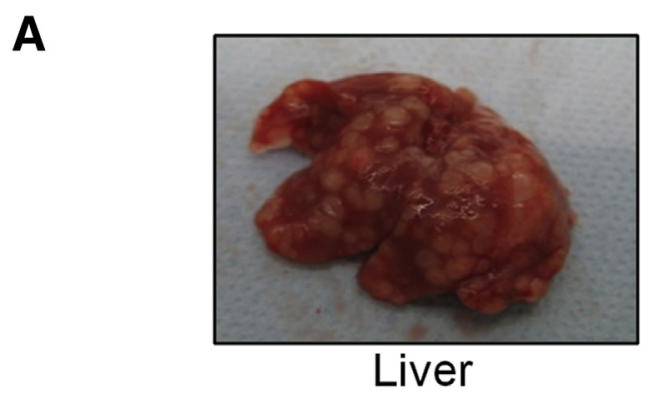

B

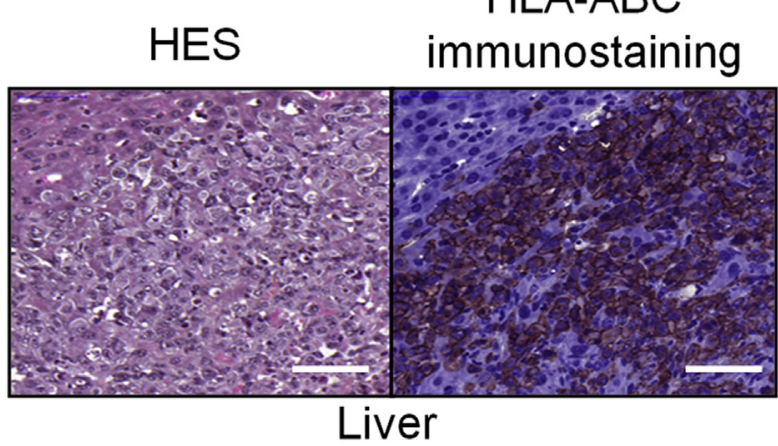

Figure 1 Efficient My-La intrahepatic xenograft mouse model. A total of $5 \times 10^{6} \mathrm{My}$-La cells were intrahepatically xenografted in adult (8 to 12

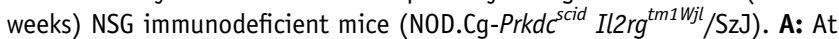
4 to 5 weeks after engraftment, mice were sacrificed and large liver tumor growth was observed, with several disseminated intrahepatic nodules. B: Mayer's hematoxylin labeling and human leukocyte antigen (HLA-ABC) immunohistochemistry on liver sections shows the presence of My-La lymphoid tumor cells. Scale bars $=50 \mu \mathrm{m}$. HES, Mayer's hematoxylin eosin and saffron.

(Table 2). This ratio indicates a large liver mass increase because of tumor formation with a loss of animal weight, representing the rapid engraftment of My-La cells.

\section{In Vitro Clonogenicity and in Vivo Intrahepatic Tumorigenicity of Seven CTCL Cell Lines}

On the basis of the above results, we hypothesized that this intrahepatic route could be efficient for six other available CTCL cell lines. Thus, four aggressive (HUT78, ${ }^{8} \mathrm{HH},{ }^{9}$ MAC2A, ${ }^{10}$ and MAC2 ${ }^{10}$ ) and two indolent CTCL cell lines (FE-PD ${ }^{11-13}$ and $\mathrm{MACl}^{10}$ ) were grafted according to the same protocol.

To compare in vitro clonogenicity of these cell lines with in vivo intrahepatic tumorigenicity, we first performed a soft agar assay for all cells using $5 \times 10^{4}, 1 \times 10^{5}$, or $5 \times 10^{5}$ cells per well of 6-well plates. Aggressive (My-La, ${ }^{7}$ HUT78, $\mathrm{HH},{ }^{9}$ and $\mathrm{MAC} 2 \mathrm{~B}^{10}$ ) and one indolent (FE-PD) ${ }^{11-13} \mathrm{CTCL}$ cell lines presented a correlation between cell growth capacity in culture and cell clonogenicity ability (Table 1). Indeed, four aggressive cell lines were able to form colonies in soft agar, whereas FE-PD, which proliferated slower in vitro compared with other cell lines, was not able to form colonies (Table 1). ${ }^{11-13}$

Regarding MAC cell lines, they exhibited different biological properties. Only MAC2B was found to be clonogenic in soft agar assay, using a high number of cells per well $\left(5 \times 10^{5}\right.$ cells), whereas MAC1 and MAC2A were not clonogenic in these conditions. Independently of their clonogenic status, all cell lines were intrahepatically xenografted in adult immunodeficient mice. Except for MAC2B, all CTCL cell lines significantly induced liver tumor formation with high reproducibility: 5 of 10 mice for FE-PD (50\%), 10 of 10 mice for MAC1 (100\%), and 10 of 10 mice for HUT78 and HH (100\%). Interestingly, although FE-PD and MAC2A cells were not clonogenic in vitro, they were tumorigenic in vivo with high incidence for FE-PD and poor incidence for MAC2A (Table 1). ${ }^{10-13}$

As well as for My-La cells, the liver/body weight ratio was higher for HUT78 $(16.91 \% \pm 4.7 \%)$, HH $(12.56 \% \pm 3.6 \%)$, and FE-PD $(6.44 \% \pm 1.8 \%)$, than in nongrafted mice control group $(4.6 \% \pm 0.5 \%)$ (Table 1$).^{7-13}$ Liver engraftment of these three cell lines led to the development of several parenchymal tumor nodules formed by HLA-positive cells displaying malignant cell criteria, such as multilobular nucleus, prominent nucleoli, and, for HUT78, numerous mitotic figures (Figures 2 and 3). Several large macroscopic nodules were observed with My-La and HUT78, whereas HH cell line exhibited a periportal mode of nodular formation with microscopic nodules (Figures 2 and 3). Conversely, a single and large tumor nodule was observed in only one MAC2A xenografted animal with abundant central necrosis and peritumoral infiltration by many polymorphonuclear leukocytes. In other animals engrafted with MAC2A cells, there was no liver tumor or infiltration (Figure 3). Only MAC1 provided a reproducible liver infiltration without tumor formation. Such infiltration corresponded to a massive sinusoidal infiltration by many tumor cells and small microscopic embolus in centrolobular veins (Figure 3). No liver tumor or infiltration was observed after engraftment with MAC2B. In comparison and despite tumorigenic capacities for MAC1 and MAC2A, a

Table 2 Efficient My-La Intrahepatic Xenograft Mouse Model

\begin{tabular}{llllll}
\hline Variable & Pathology & $\begin{array}{l}\text { Liver macroscopic } \\
\text { tumor }\end{array}$ & $\begin{array}{l}\text { Mice liver/body } \\
\text { weight ratio (\%) }\end{array}$ & $\begin{array}{l}\text { Xenograft reproducibility } \\
\text { (mice no.) }\end{array}$ & $\begin{array}{l}\text { Intrahepatic xenograft } \\
\text { efficiency }\end{array}$ \\
\hline Control & NA & No & $4.60 \pm 0.5$ & NA & NA \\
My-La & T-MF & Yes & $13.77 \pm 3.0^{* * *}$ & $60 / 60$ & $100 \%$ \\
\hline
\end{tabular}

Mice liver/body weight ratio was calculated and reproducibility of experiments was determined; $100 \%$ of the mice (60/60) developed liver tumors. $* * * P<0.001$

NA, not applicable; T-MF, transformed mycosis fungoides. 

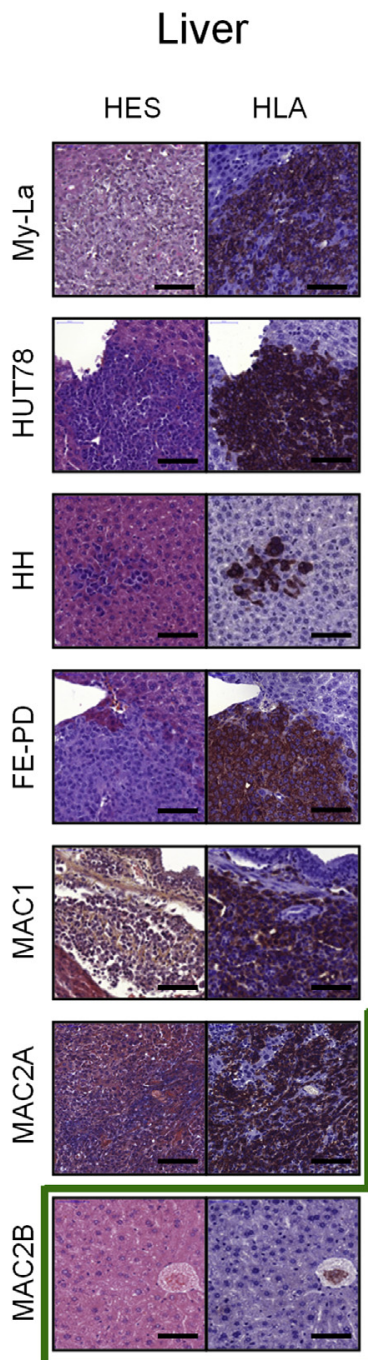

Kidney

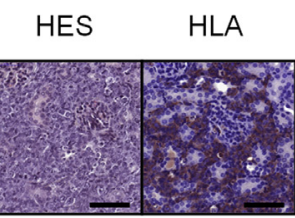

Spleen
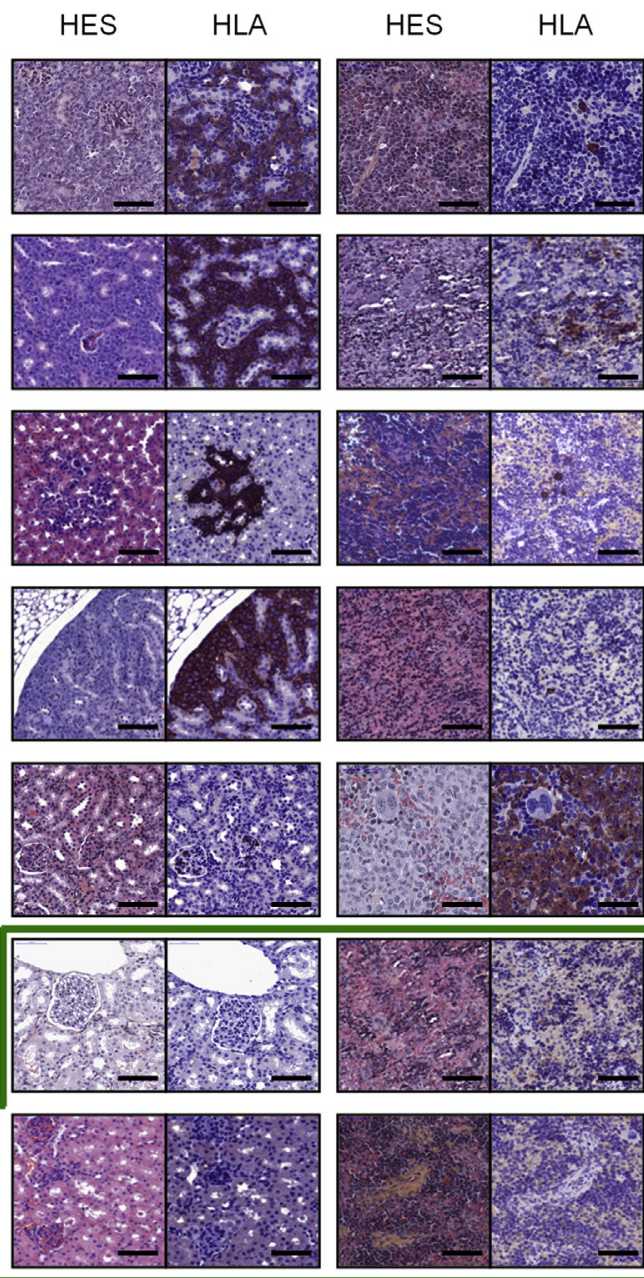

Lungs
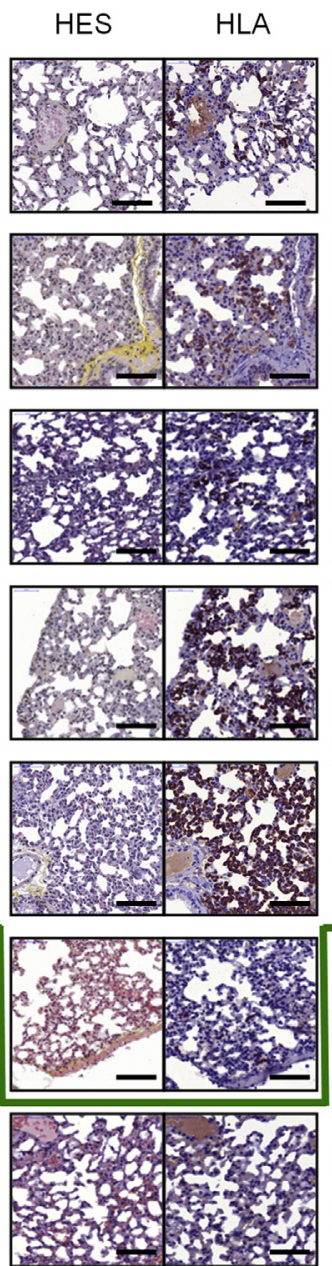

Heart

HES HLA
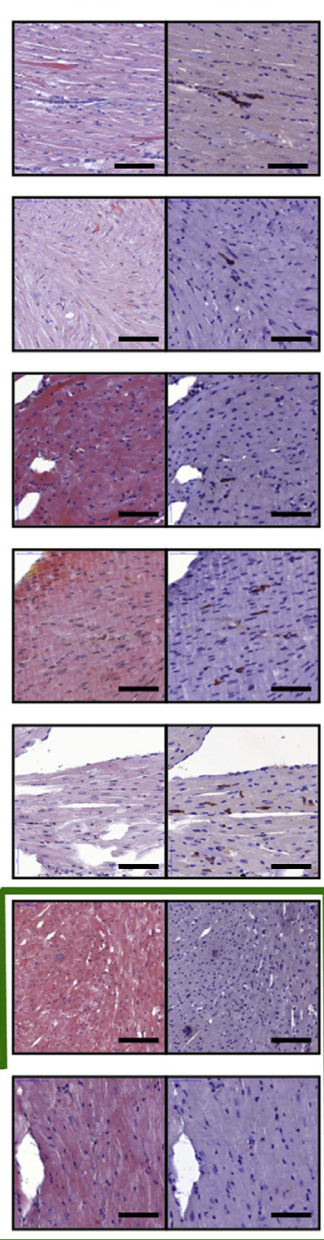

Figure 2 Human leukocyte antigen (HLA-ABC) immunohistochemistry (IHC) in mice tissues after CTCL intrahepatic xenografts. Formalin-fixed, paraffinembedded tissue sections were deparaffinized, and IHC was performed with a HLA-ABC antibody (Ab70328). Sections were counterstained with Mayer's hematoxylin (HES). The green outline surrounds images that present a negative HLA-ABC immunostaining. Scale bars $=50 \mu \mathrm{m}$.

significant enhancement of the liver/body weight ratio was only observed for MAC1 $(6.01 \% \pm 0.5 \%)$. A similar liver/ body weight ratio and sinusoidal pattern of infiltration was shown for the FE-PD cell line (Figure 3).

Altogether, the model was successful for six of the seven CTCL cell lines tested. The rate of CTCL engraftment was 96 of 120 mice $(80 \%)$.

\section{CTCL Intrahepatic Xenografts Induce Metastases}

Intrahepatic xenograft is a common mouse model for hepatocellular carcinoma research ${ }^{23}$ generally performed in athymic or immunodeficient mice. Because this model is informative for metastatic spreading properties of tumor cells, we chose to systematically analyze kidneys, spleen, lungs, and heart after CTCL intrahepatic xenografts both macroscopically and after HLA-ABC immunostaining of organ sections (Figure 2). Histological analysis of organs is presented as tumor/infiltrate/ embolus in Table 3.

For My-La, HUT78, HH, and FE-PD, liver enlargement or tumor formation was associated with bilateral kidney colonization macroscopically detected at sacrifice (Figure 1A). Indeed, both kidneys of engrafted animals appeared less vascularized than in control mice, and tumor cell infiltration of the cortex was visible at the microscopic level (Figures 2 and 3). With the My-La cell line, a subcapsular infiltration by microscopic nodules corresponded to a generalized cortical infiltration of kidneys. For HUT78, HH, and FE-PD cell lines, HLA-ABC positive cells were detected on sections with a predominant infiltration of the cortical zone with clusters between glomeruli and tubules. The MAC1 cell line provided a predominant mode of vascular infiltration with numerous intravascular emboli and a specific mesangial infiltration of the glomeruli (Figure 2 and Supplemental Figure S1). There was no kidney involvement with 

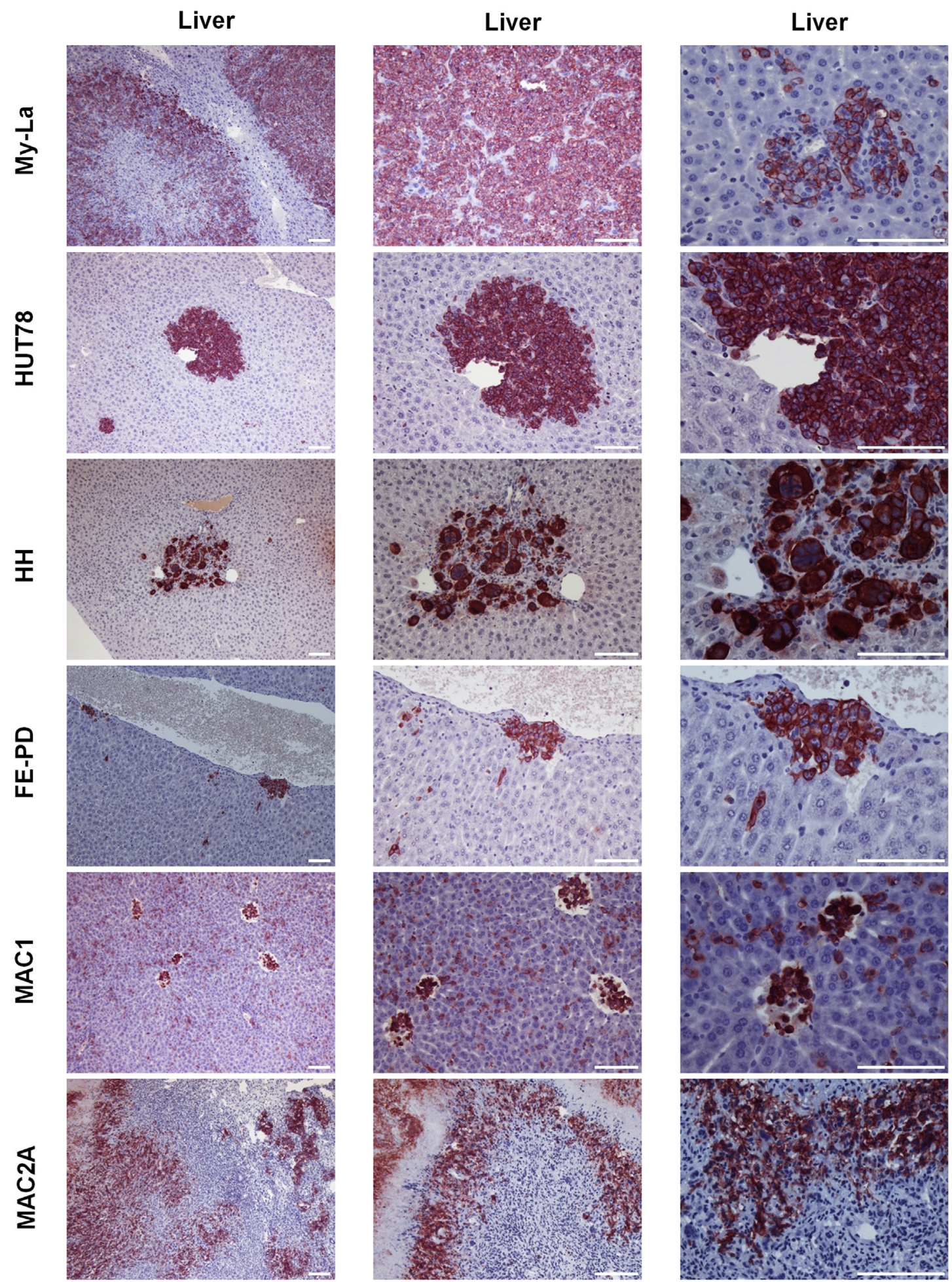

Figure 3 Human leukocyte antigen (HLA-ABC) immunostaining by immunohistochemistry (IHC) in livers. Mice were intrahepatically xenografted with CTCL cell lines: My-La, HUT78, HH, FE-PD, MAC1, and MAC2A. After animal sacrifice, formalin-fixed, paraffin-embedded tissue sections were deparaffinized, and IHC was performed with a HLA-ABC antibody (Ab70328). Images were captured with a LEICA DMR microscope coupled with a NIKON DS-FI2 camera and analyzed with NIS $\mathrm{BR}$ imaging software. Scale bars $=100 \mu \mathrm{m}$. Original magnification: $\times 10$ (left column); $\times 20$ (middle column); $\times 40$ (right column).

MAC2A or MAC2B cell lines except the presence of rare human cells in the vessels for MAC2A cell line. Although no infiltration was seen for MAC2A and MAC2B cell lines in spleen, CTCL cells were present in the sinusoids of the red pulp after engraftment with My-La, HUT78, HH, FE-PD, and MAC1 cell lines (Figure 2 and Supplemental Figure S1). Spleen involvement was also associated with involvement of Billroth's cords, as seen with HUT78 cell line (Supplemental 
Table 3 Histological Analysis of Tumor Cell Spreading in Mice Tissues after CTCL Intrahepatic Xenografts

\begin{tabular}{|c|c|c|c|c|c|c|c|c|c|c|c|}
\hline \multirow{2}{*}{$\begin{array}{l}\text { CTCL cell } \\
\text { line }\end{array}$} & \multirow[b]{2}{*}{ Pathology } & \multicolumn{5}{|c|}{ HLA-ABC-positive cells in tissues of 10 mice } & \multicolumn{5}{|c|}{ Cell spreading in organs (embolus/infiltrate/tumor) } \\
\hline & & Liver & Spleen & Kidneys & Lungs & Heart & Liver & Spleen & Kidneys & Lungs & Heart \\
\hline \multicolumn{12}{|c|}{ Aggressive CTCL } \\
\hline HUT78 & SS & $10 / 10$ & $8 / 10$ & $8 / 10$ & $5 / 10$ & $4 / 10$ & $T / E$ & I & $\mathrm{T} / \mathrm{E}$ & $\mathrm{T} / \mathrm{E}$ & $E$ \\
\hline $\mathrm{HH}$ & cATLL & $10 / 10$ & $10 / 10$ & $10 / 10$ & $9 / 10$ & $9 / 10$ & $\mathrm{~T} / \mathrm{I}$ & I & $\mathrm{I} / \mathrm{E}$ & I & $\mathrm{E}$ \\
\hline $\mathrm{MAC2A}$ & $\mathrm{CD}^{+} 0^{+} \mathrm{ALCL}$ & $1 / 10$ & $0 / 10$ & $0 / 10$ & $1 / 10$ & $0 / 10$ & $\mathrm{~T}$ & & & $\mathrm{E}$ & \\
\hline FE-PD & $\mathrm{CD}^{2} 0^{+} \mathrm{ALCL}$ & $5 / 10$ & $5 / 10$ & $4 / 10$ & $5 / 10$ & $5 / 10$ & $\mathrm{I} / \mathrm{E}$ & E & $\mathrm{T} / \mathrm{E}$ & I & $E$ \\
\hline MAC1 & $\mathrm{CD}^{\circ} 0^{+} \mathrm{ALCL}$ & $10 / 10$ & $8 / 10$ & $7 / 10$ & $8 / 10$ & $8 / 10$ & $\mathrm{I} / \mathrm{E}$ & $\mathrm{I}++$ & $\mathrm{I} / \mathrm{E}$ & $\mathrm{I} / \mathrm{E}$ & $E$ \\
\hline
\end{tabular}

ALCL, anaplastic large cell lymphoma; cATLL, cutaneous adult T-cell leukemia/lymphoma; CTCL, cutaneous T-cell lymphoma; E, embolus; HLA-ABC, human leukocyte antigen; I, infiltrate; SS, Sézary syndrome; T, tumor; T-MF, transformed mycosis fungoides.

Figure S1). A massive and diffuse infiltration of the red pulp was observed for MAC1. Regarding the lungs, a massive and generalized infiltration was observed in all grafted mice with My-La, HUT78, HH, FE-PD, and MAC1 cell lines, and in one mouse grafted with MAC2A. This infiltration mainly involved the alveoli septa and was sometimes associated with capillaries' dilatation and fibrosis. The MAC1 cell line exhibited again a specific tropism with both septa infiltration and replacement of alveolar cells in a lepidic mode. Finally, no heart infiltration was observed, only sporadic cells were seen in the capillaries between cardiomyocytes for MAC1 (data not shown).
A

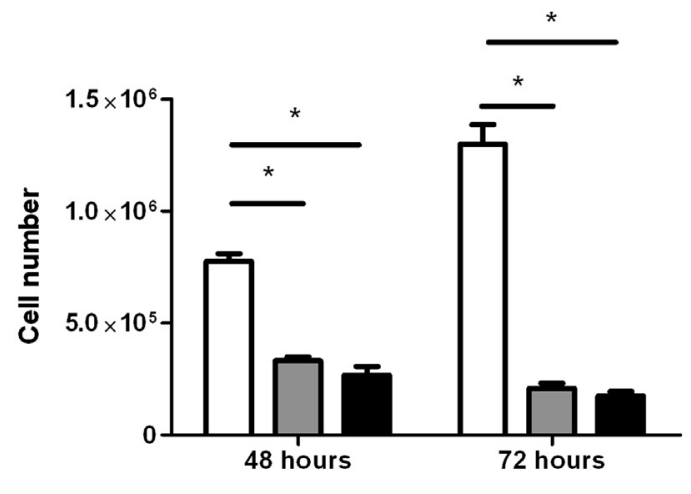

$\square$ Untreated $\square$ MTX $10 \mu \mathrm{mol} / \mathrm{L} \square$ MTX $50 \mu \mathrm{mol} / \mathrm{L}$

C

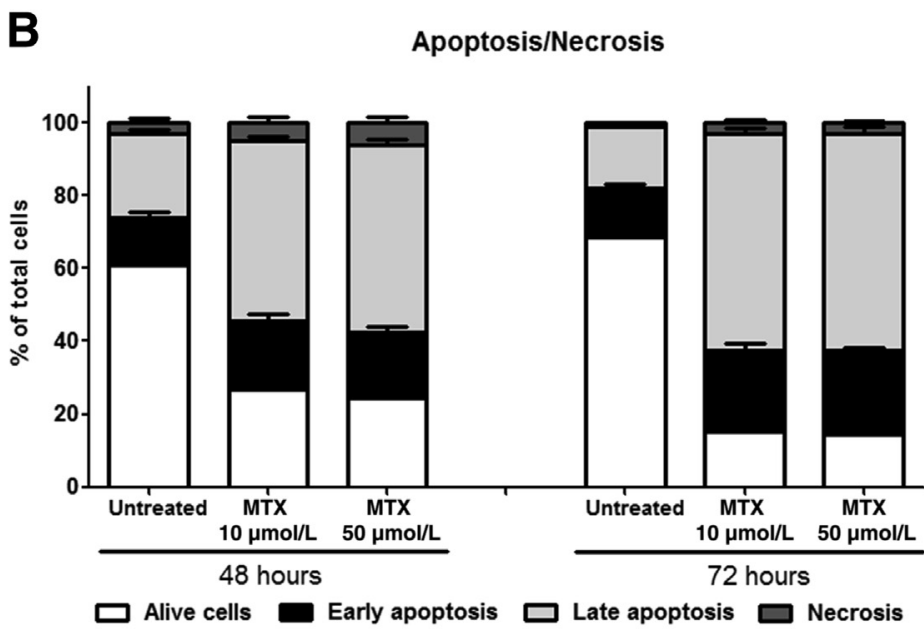

72 hours

MTX $10 \mu \mathrm{mol} / \mathrm{L}$
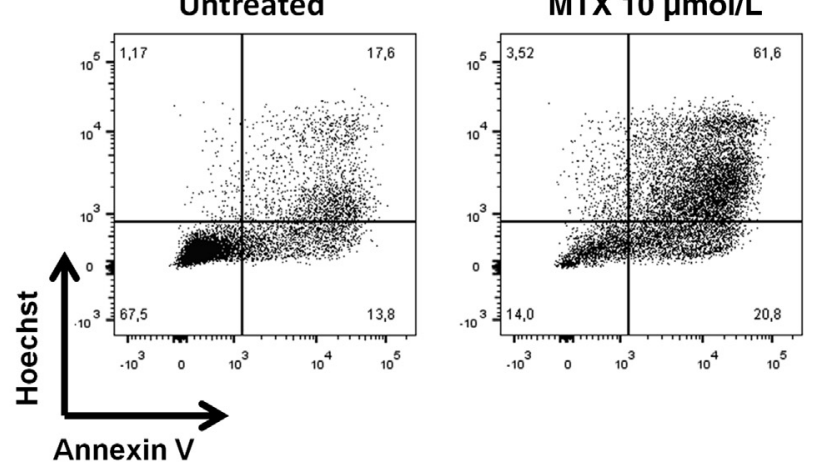

MTX $50 \mu \mathrm{mol} / \mathrm{L}$

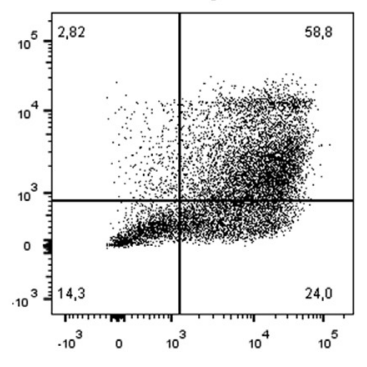

Figure 4 Methotrexate induces apoptosis/necrosis in My-La cells. A: My-La cells were cultured in RPMI 1640 medium with $10 \%$ fetal bovine serum and treated with methotrexate (MTX; 10 or $50 \mu \mathrm{mol} / \mathrm{L}$ ) or left untreated. Cells were counted after 48 and 72 hours of incubation with or without MTX. B: Apoptosis/necrosis analysis of My-La cells after 48 and 72 hours of culture with or without 10 or $50 \mu \mathrm{mol} / \mathrm{L}$ MTX. Proportions of alive, early/late apoptotic, and necrotic cells were evaluated by annexin $V$ and Hoechst 33342 staining and analyzed by fluorescence-activated cell sorting. C: Dot plots are representative of cell viability after 72 hours in culture for each condition. Apoptotic/necrotic cell proportion was measured using annexin $\mathrm{V}-\mathrm{PE}$ and Hoechst, respectively. ${ }^{\star} P<0.05$. 
A

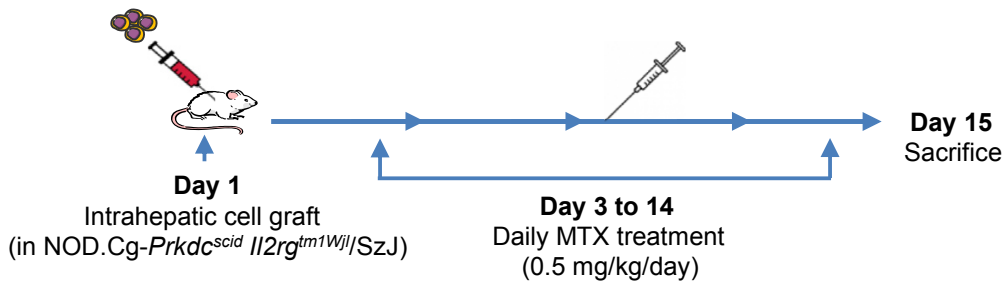

B

HLA-ABC immunostaining

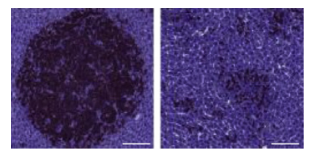

Control MTX

C

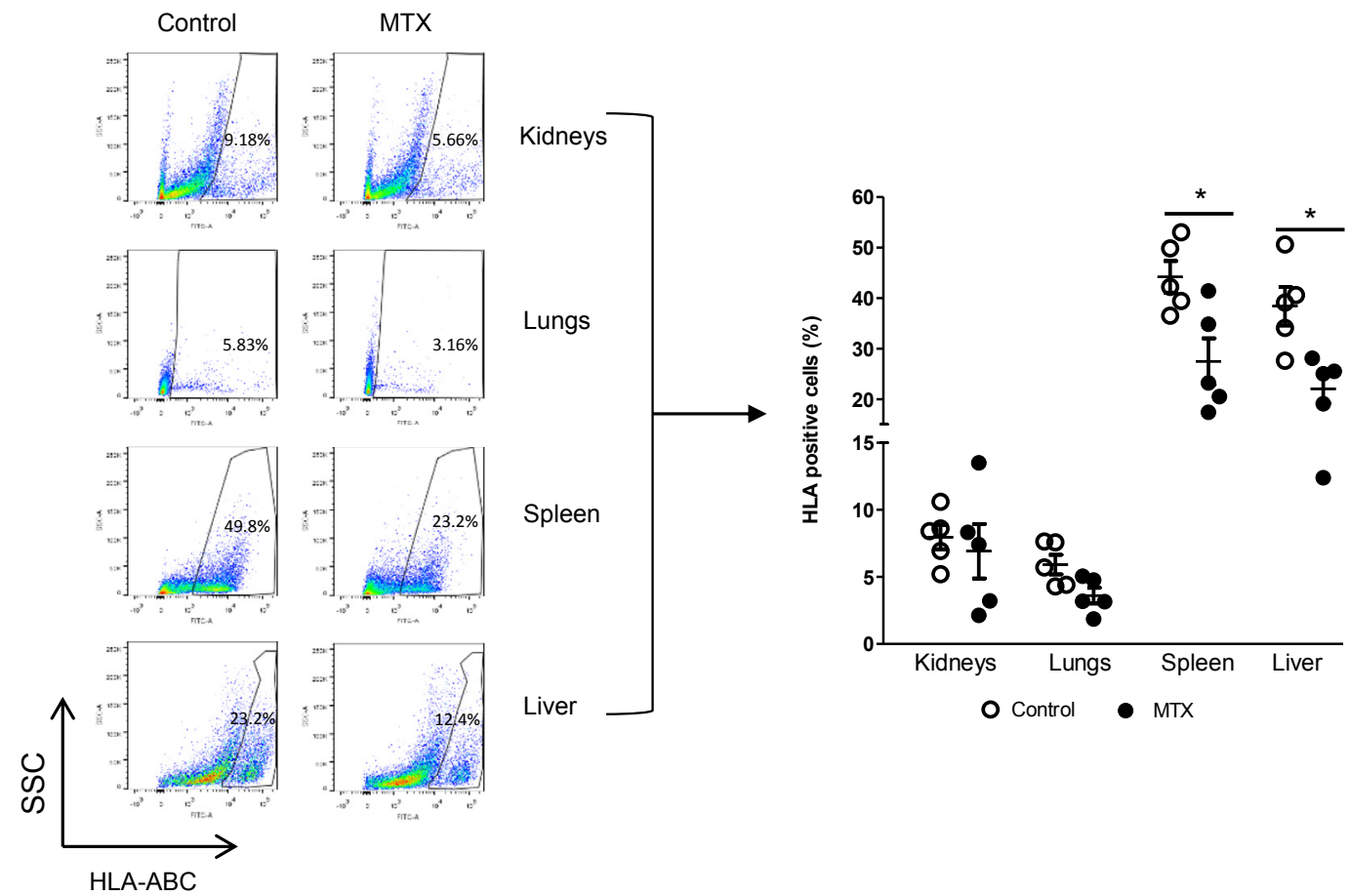

Figure 5 CTCL intrahepatic xenograft, a useful model for in vivo preclinical study. A: Intrahepatic xenograft and methotrexate (MTX) in vivo treatment procedure. B: Methotrexate treatment strongly diminished liver tumor formation, as observed by a decrease of human leukocyte antigen (HLA-ABC) staining in liver sections by immunohistochemistry (IHC). C: HLA-ABC was detected by fluorescence-activated cell sorter analysis in mice tissues. A decrease of HLA-ABC positive cells in lungs, spleen, and liver in MTX treated mice is observed. Dot plots represent cell granularity [Side SCater (SSC) along y axis] versus HLA-ABC expression ( $x$ axis). Data are given as means \pm SEM. ${ }^{*} P<0.05$. Scale bars $=100 \mu \mathrm{m}$.

\section{A Model for Rapid Therapeutic Evaluation in CTCL}

Methotrexate is a cytotoxic chemotherapy described as anticancer treatment in solid tumors (breast, head and neck, lung, stomach, and esophagus) also used to treat acute

Table 4 Methotrexate Treatment in Mice Engrafted Intrahepatically

\begin{tabular}{llll}
\hline & Mice & Liver & Liver/body \\
average & average & weight \\
Variable & weight $(\mathrm{g})$ & weight $(\mathrm{g})$ & ratio $(\%)$ \\
\hline
\end{tabular}

My-La control $\quad 26.12 \pm 1.03 .38 \pm 0.312 .95 \pm 1.3$

My-La + methotrexate $29.82 \pm 1.42 .18 \pm 0.1 \quad 7.32 \pm 0.5^{* * *}$

Ten adult mice were engrafted intrahepatically with $2.5 \times 10^{6} \mathrm{My}$-La cells. Starting day 3, mice were treated with $0.5 \mathrm{mg} / \mathrm{kg}$ of methotrexate (or dimethyl sulfoxide as control) during 12 days. At the end of experiment (day 15), mice were sacrificed, and liver/body weight ratio was determined. Data are expressed as means \pm SD.

$* * * P<0.001$ lymphoblastic leukemia and non-Hodgkin lymphoma as CTCL patients. ${ }^{24}$ We first studied in vitro the impact of MTX treatment on My-La cells using 10 and $50 \mu \mathrm{mol} / \mathrm{L}$ of MTX. We observed that MTX treatment decreased significantly My-La cell number in culture, as soon as 48 hours, irrespective of the MTX dose tested (Figure 4A). Cell number diminution was associated with a higher proportion of late apoptotic cells after MTX treatment. Indeed, proportions of annexin V/Hoechst-positive cells were increased in MTX-treated cells compared with untreated cells (Figure 4, B and C, and Supplemental Figure S2), confirming a previous in vitro report. ${ }^{25}$ Then, we used MTX to validate our in vivo intrahepatic model of CTCL in a preclinical study. My-La cells were xenografted intrahepatically at $2.5 \times 10^{6}$ in adult mice at day 1 (Figure 5A). Starting day 3 , mice were daily treated intraperitoneally with $0.5 \mathrm{mg} / \mathrm{kg}$ of MTX or left untreated (in control mice) during 12 days. At day 15, mice were sacrificed (Figure 5A), body and liver weights were measured (Table 4), organs were 
mechanically dissociated in single-cell suspension, and HLA-ABC-positive cells were detected by FACS analysis. MTX treatment efficiently inhibited liver tumor formation of My-La cells, as shown by the decrease of liver/body weight ratio in MTX-treated mice (Table 4). This was confirmed by HLA-ABC-positive cells and FACS analysis (Figure 5, B and C). Moreover, MTX treatment significantly reduced My-La cells spreading in spleen and liver (Figure 5C), whereas no effect was observed for organs with low infiltration (Figure 5C). Taken together, these results indicate that the intrahepatic mouse model for CTCL is a robust model for rapid in vivo evaluation of therapeutic efficiency on tumor formation, migration or spreading capacities, and organ infiltration.

\section{Discussion}

For the past 10 years, few articles reported mouse xenograft models of fresh CTCL patient cells or cell lines. ${ }^{15-20}$ These models were based on a small number of animals and a highly variable rate of engraftment appeared to be mouse strain and cell line dependent. Indeed, most engraftments were obtained using My-La cells, an aggressive transformed MF cell line. ${ }^{14-20}$ For other CTCL cell lines, in 2010, Doebbeling ${ }^{20}$ obtained a low rate of engraftment in CB-17 mice (CB-17//cr.Cg-Prkdc ${ }^{\text {scid }} L y s t^{\mathrm{bg}} / \mathrm{Crl}$ ), in two of seven mice for HUT78 and zero of seven for SeAx (another SS cell line) underlining the absence of reproducible model for CTCL cell line engraftment.

Because CTCL are primary skin diseases, the subcutaneous site was primarily chosen for injection of aggressive CTCL cells My-La, HUT78, SeAx, or HH, although most of these cells derived from blood circulating tumor T-cells. ${ }^{7-11}$ The My-La cell line was widely used for local tumorigenesis evaluation in subcutaneous models, and there was no evidence of extracutaneous spreading or metastases. ${ }^{14-20}$ So far, only one study reported liver infiltration after subcutaneous injection of HH cells into NOG mice. ${ }^{16}$ Although a subcutaneous site facilitates tumor growth monitoring, this does neither represent a physiological site nor an ideal niche for the expansion of CTCL cell lines. Indeed, most experiments consisting in subcutaneous injection of fresh cells from patients or CTCL cell lines in immunodeficient mice failed. Others used intravenous injection in severe combined immunodeficiency mice of $\mathrm{HH}$ cell for therapeutic evaluation, but did not report visceral infiltration. ${ }^{17}$ We hypothesized that CTCL cells may need an appropriate homing site delivering the necessary growth factors and thus considered intrahepatic mouse route as interesting for CTCL in which malignant T-cells often circulate. ${ }^{26} \mathrm{It}$ is known that with advanced stages of CTCL disease, liver is an organ where CTCL cells accumulated. ${ }^{27}$ Moreover, liver is a wellvascularized organ that can provide essential cytokines for CTCL cell proliferation and tumor growth. Intrahepatic mouse models are widely used to study hepatocellular carcinoma local development and metastatic potential. ${ }^{23}$ Indeed, van der Fits et $\mathrm{al}^{22}$ were the first to use such liver injection of CTCL in newborn mice. This model was originally developed for human immune system reconstitution in sublethally irradiated newborn mice engrafted with human $\mathrm{CD}_{3} 4^{+}$progenitor cells with a high rate $(>80 \%$ after 8 weeks) of engraftment. ${ }^{28}$ Despite its interest for CD34 ${ }^{+}$ progenitor cell engraftment, this model exhibited some clear technical limits for the expansion of differentiated or memory neoplastic T-cells. First, handling and grafting mice at this age (2 to 7 days old) present an evident high risk of animal death after injection. Second, the injected volume had to be reduced according to the small liver size, leading to a reduction of injected cell number, which may be critical for the engraftment of cells with low proliferative or selfrenewal capacities. Finally, it only worked for two SS cell lines (HUT78 and SeAx) with a small number of animals and has so far not been successfully reproduced for engraftment of other CTCL cell lines or fresh primary CTCL cells.

In this study, we generated a mouse model for aggressive (My-La, HUT78, HH, MAC2A, and MAC2B) and indolent (FE-PD and MAC1) CTCL cell line engraftment. To the best of our knowledge, this is the first report of a working in vivo mouse model for FE-PD and MAC2A cells. With this model, cell spreading in mice organs like kidneys, lungs, spleen, and heart was variable for each cell line. These differences in migration/spreading capacities could be explained by CTCL subtype (SS, CD30 ${ }^{+}$ALCL, or transformed MF), cell origin (peripheral blood, tumor, plaque), and specific cell surface molecule expression. ${ }^{29}$ Indeed, MAC cell lines were generated by Kadin et $\mathrm{al}^{10}$ from the same patient at different time of the disease and, more important, at different body locations. Thus, MAC1 was obtained at early stage during the indolent phase from peripheral blood of a CD30 $0^{+}$ALCL, whereas MAC2A and MAC2B were obtained from two individual skin tumors at aggressive terminal stage. ${ }^{30}$ We hypothesized that MAC1 cell line originating from the blood retains a capacity to infiltrate hepatic, renal, and splenic sinusoids and centrolobular hepatic veins via endothelial cell addressins. Taken together, these results demonstrated that intrahepatic xenografts in adult immunodeficient mice are an efficient model to evaluate differences in CTCL tumorigenicity, migration, and spreading capacities. This may permit the evaluation of imaging or monitoring methods of CTCL cells. The use of our model for patient-derived CTCL xenografts may also facilitate the generation of new cutaneous lymphoma cell lines. However, a humanized bed could be necessary for the successful engraftment of fresh patient CTCL cells, as reported for human primary squamous carcinoma cells. ${ }^{31}$ For now, because of a lack of a relevant model to test drugs targeting CTCL, preclinical in vivo studies are realized with nonappropriate surrogate models. For example, a recent evaluation of the in vivo activity of a humanized KIR3DL2 antibody against CTCL required the 
ectopic expression of this marker in a B-cell lymphoma cell line before mice engraftment. ${ }^{32}$

In conclusion, this intrahepatic mouse model is an efficient model that can be used for extended in vivo preclinical studies. Therefore, this new model may be used for in vivo screening of therapeutic molecules in different compartments, as observed herein with methotrexate. This model also allows further functional investigations that may lead to a better understanding of the genomic and biological hallmarks of the different CTCL subtypes. ${ }^{33}$

\section{Acknowledgments}

We thank Bordeaux University Federative Structure of Research Transbiomed for the use of the cytometry platform and A2 animal housing facility, Dr. Vincent Servant for providing methotrexate, and Dr. Anne Pham-Ledard and Prof. Pierre Dubus for their constant help to the cutaneous lymphoma project and general helpful advice.

\section{Supplemental Data}

Supplemental material for this article can be found at http://dx.doi.org/10.1016/j.ajpath.2016.03.012.

\section{References}

1. Rook AH, Gottlieb SL, Wolfe JT, Vowels BR, Sood SS, Niu Z, Lessin SR, Fox FE: Pathogenesis of cutaneous T-cell lymphoma: implications for the use of recombinant cytokines and photopheresis. Clin Exp Immunol 1997, 107(Suppl 1):16-20

2. Watanabe R, Gehad A, Yang C, Scott LL, Teague JE, Schlapbach C, Elco CP, Huang V, Matos TR, Kupper TS, Clark RA: Human skin is protected by four functionally and phenotypically discrete populations of resident and recirculating memory T cells. Sci Transl Med 2015, 7: 279ra239

3. Willemze R, Jaffe ES, Burg G, Cerroni L, Berti E, Swerdlow SH, Ralfkiaer E, Chimenti S, Diaz-Perez JL, Duncan LM, Grange F, Harris NL, Kempf W, Kerl H, Kurrer M, Knobler R, Pimpinelli N, Sander C, Santucci M, Sterry W, Vermeer MH, Wechsler J, Whittaker S, Meijer CJ: WHO-EORTC classification for cutaneous lymphomas. Blood 2005, 105:3768-3785

4. Bekkenk MW, Geelen FA, van Voorst Vader PC, Heule F, Geerts ML, van Vloten WA, Meijer CJ, Willemze R: Primary and secondary cutaneous $\mathrm{CD} 30(+)$ lymphoproliferative disorders: a report from the Dutch Cutaneous Lymphoma Group on the long-term follow-up data of 219 patients and guidelines for diagnosis and treatment. Blood 2000, 95:3653-3661

5. Clark RA, Watanabe R, Teague JE, Schlapbach C, Tawa MC, Adams N, Dorosario AA, Chaney KS, Cutler CS, Leboeuf NR, Carter JB, Fisher DC, Kupper TS: Skin effector memory T cells do not recirculate and provide immune protection in alemtuzumab-treated CTCL patients. Sci Transl Med 2012, 4:117ra117

6. Delfau-Larue MH, Laroche L, Wechsler J, Lepage E, Lahet C, AssoBonnet M, Bagot M, Farcet JP: Diagnostic value of dominant T-cell clones in peripheral blood in 363 patients presenting consecutively with a clinical suspicion of cutaneous lymphoma. Blood 2000, 96: 2987-2992

7. Kaltoft K, Bisballe S, Dyrberg T, Boel E, Rasmussen PB, ThestrupPedersen K: Establishment of two continuous T-cell strains from a single plaque of a patient with mycosis fungoides. In Vitro Cell Dev Biol 1992, 28A:161-167

8. Bunn PA Jr, Foss FM: T-cell lymphoma cell lines (HUT102 and HUT78) established at the National Cancer Institute: history and importance to understanding the biology, clinical features, and therapy of cutaneous T-cell lymphomas (CTCL) and adult T-cell leukemialymphomas (ATLL). J Cell Biochem Suppl 1996, 24:12-23

9. Starkebaum G, Loughran TP Jr, Waters CA, Ruscetti FW: Establishment of an IL-2 independent, human T-cell line possessing only the p70 IL-2 receptor. Int J Cancer 1991, 49:246-253

10. Kadin ME, Cavaille-Coll MW, Gertz R, Massague J, Cheifetz S, George D: Loss of receptors for transforming growth factor beta in human T-cell malignancies. Proc Natl Acad Sci U S A 1994, 91: 6002-6006

11. del Mistro A, Leszl A, Bertorelle R, Calabro ML, Panozzo M, Menin C, D'Andrea E, Chieco-Bianchi L: A CD30-positive T cell line established from an aggressive anaplastic large cell lymphoma, originally diagnosed as Hodgkin's disease. Leukemia 1994, 8: 1214-1219

12. Dirks WG, Zaborski M, Jager K, Challier C, Shiota M, Quentmeier H, Drexler HG: The $(2 ; 5)(\mathrm{p} 23 ; \mathrm{q} 35)$ translocation in cell lines derived from malignant lymphomas: absence of $\mathrm{t}(2 ; 5)$ in Hodgkin-analogous cell lines. Leukemia 1996, 10:142-149

13. Drexler HG, MacLeod RA: Malignant hematopoietic cell lines: in vitro models for the study of anaplastic large-cell lymphoma. Leukemia 2004, 18:1569-1571

14. Chevret E, Andrique L, Prochazkova-Carlotti M, Ferrer J, Cappellen D, Laharanne E, Idrissi Y, Boettiger A, Sahraoui W, Ruiz F, Pham-Ledard A, Vergier B, Belloc F, Dubus P, BeylotBarry M, Merlio JP: Telomerase functions beyond telomere maintenance in primary cutaneous T-cell lymphoma. Blood 2014, 123: $1850-1859$

15. Tun-Kyi A, Qin JZ, Oberholzer PA, Navarini AA, Hassel JC, Dummer R, Dobbeling U: Arsenic trioxide down-regulates antiapoptotic genes and induces cell death in mycosis fungoides tumors in a mouse model. Ann Oncol 2008, 19:1488-1494

16. Ito $\mathrm{A}$, Ishida $\mathrm{T}$, Utsunomiya $\mathrm{A}$, Sato $\mathrm{F}$, Mori $\mathrm{F}$, Yano $\mathrm{H}$, Inagaki $\mathrm{A}$, Suzuki S, Takino H, Ri M, Kusumoto S, Komatsu H, Iida S, Inagaki H, Ueda R: Defucosylated anti-CCR4 monoclonal antibody exerts potent ADCC against primary ATLL cells mediated by autologous human immune cells in NOD/Shi-scid, IL-2R gamma(null) mice in vivo. J Immunol 2009, 183:4782-4791

17. Yano $\mathrm{H}$, Ishida $\mathrm{T}$, Inagaki $\mathrm{A}$, Ishii $\mathrm{T}$, Ding $\mathrm{J}$, Kusumoto $\mathrm{S}$, Komatsu H, Iida S, Inagaki H, Ueda R: Defucosylated anti CC chemokine receptor 4 monoclonal antibody combined with immunomodulatory cytokines: a novel immunotherapy for aggressive/ refractory Mycosis fungoides and Sezary syndrome. Clin Cancer Res 2007, 13:6494-6500

18. Thaler S, Burger AM, Schulz T, Brill B, Bittner A, Oberholzer PA, Dummer R, Schnierle BS: Establishment of a mouse xenograft model for mycosis fungoides. Exp Dermatol 2004, 13:406-412

19. Krejsgaard T, Kopp K, Ralfkiaer E, Willumsgaard AE, Eriksen KW, Labuda T, Rasmussen S, Mathiesen AM, Geisler C, Lauenborg B, Becker JC, Zhang Q, Wasik MA, Odum N, Woetmann A: A novel xenograft model of cutaneous T-cell lymphoma. Exp Dermatol 2010, 19:1096-1102

20. Doebbeling U: A mouse model for the Sezary syndrome. J Exp Clin Cancer Res 2010, 29:11

21. Han T, Abdel-Motal UM, Chang DK, Sui J, Muvaffak A, Campbell J, Zhu Q, Kupper TS, Marasco WA: Human anti-CCR4 minibody gene transfer for the treatment of cutaneous T-cell lymphoma. PLoS One 2012, 7:e44455

22. van der Fits L, Rebel HG, Out-Luiting JJ, Pouw SM, Smit F, Vermeer KG, van Zijl L, Tensen CP, Weijer K, Vermeer MH: A novel mouse model for Sezary syndrome using xenotransplantation of Sezary cells into immunodeficient RAG2(-/-) gammac(-/-) mice. Exp Dermatol 2012, 21:706-709 
23. Heindryckx F, Colle I, Van Vlierberghe H: Experimental mouse models for hepatocellular carcinoma research. Int J Exp Pathol 2009, 90:367-386

24. Zackheim HS, Kashani-Sabet M, Hwang ST: Low-dose methotrexate to treat erythrodermic cutaneous T-cell lymphoma: results in twentynine patients. J Am Acad Dermatol 1996, 34:626-631

25. Wu J, Salva KA, Wood GS: c-CBL E3 ubiquitin ligase is overexpressed in cutaneous T-cell lymphoma: its inhibition promotes activation-induced cell death. J Invest Dermatol 2015, 135:861-868

26. Beylot-Barry M, Sibaud V, Thiebaut R, Vergier B, Beylot C, Delaunay M, Chene G, Dubus P, Merlio JP: Evidence that an identical $\mathrm{T}$ cell clone in skin and peripheral blood lymphocytes is an independent prognostic factor in primary cutaneous $\mathrm{T}$ cell lymphomas. J Invest Dermatol 2001, 117:920-926

27. Huberman MS, Bunn PA Jr, Matthews MJ, Ihde DC, Gazdar AF, Cohen MH, Minna JD: Hepatic involvement in the cutaneous T-cell lymphomas: results of percutaneous biopsy and peritoneoscopy. Cancer 1980, 45:1683-1688

28. Legrand N, Weijer K, Spits H: Experimental models to study development and function of the human immune system in vivo. J Immunol 2006, 176:2053-2058
29. Jain S, Stroopinsky D, Yin L, Rosenblatt J, Alam M, Bhargava P Clark RA, Kupper TS, Palmer K, Coll MD, Rajabi H, Pyzer A, Bar-Natan M, Luptakova K, Arnason J, Joyce R, Kufe D, Avigan D: Mucin 1 is a potential therapeutic target in cutaneous T-cell lymphoma. Blood 2015, 126:354-362

30. Ehrentraut S, Nagel S, Scherr ME, Schneider B, Quentmeier H, Geffers R, Kaufmann M, Meyer C, Prochorec-Sobieszek M, Ketterling RP, Knudson RA, Feldman AL, Kadin ME, Drexler HG, MacLeod RA: t(8;9)(p22;p24)/PCM1-JAK2 activates SOCS2 and SOCS3 via STAT5. PLoS One 2013, 8:e53767

31. Patel GK, Yee CL, Yuspa SH, Vogel JC: A humanized stromal bed is required for engraftment of isolated human primary squamous cell carcinoma cells in immunocompromised mice. J Invest Dermatol 2012, $132: 284-290$

32. Marie-Cardine A, Viaud N, Thonnart N, Joly R, Chanteux S, Gauthier L, Bonnafous C, Rossi B, Blery M, Paturel C, Bensussan A, Bagot M, Sicard H: IPH4102, a humanized KIR3DL2 antibody with potent activity against cutaneous T-cell lymphoma. Cancer Res 2014, 74:6060-6070

33. Hanahan D, Weinberg RA: Hallmarks of cancer: the next generation. Cell 2011, 144:646-674 